\title{
Michael Blauth, Stephen L. Kates, Joseph A. Nicholas: Osteoporotic fracture care medical and surgical management (with e-book)
}

\section{Thieme Verlag, New York, Stuttgart, Delhi, Rio de Janeiro, 2018, 610 pp, 1000 figs., Hardcover, EUR (D) 164,99 EUR (A) 169,70 CHF 190,00, ISBN: 978-3-13-242751-8}

\author{
Alain G. Graftiaux ${ }^{1}$ - Pierre H. Kehr ${ }^{1}$
}

Received: 27 February 2019 / Accepted: 20 July 2019 / Published online: 25 July 2019

(c) Springer-Verlag France SAS, part of Springer Nature 2019

This book describes the peculiarities of the management of fractures in the elderly, contrary to the usual trauma books which more often deal with young subjects with high-energy trauma.

The first part concerns the peculiarities of the care of elderly subjects from a medical and surgical point of view, but also from the whole environment of malnutrition, polytreatment, etc.

The second part concerns recommendations to optimize the management of these patients.

The last part deals with the management of the different types of fractures according to the bones and joints, describing the different means and indications that are not necessarily always superimposable to the treatment in younger subjects.
This very didactic book will allow everyone to discover or deepen the elements of care for these particular and fragile patients.

On the other hand, internet access is provided to complete the book.

\section{Compliance with ethical standards}

Conflict of interest The authors declare that they have no competing interests.

Publisher's Note Springer Nature remains neutral with regard to jurisdictional claims in published maps and institutional affiliations.
Pierre H. Kehr

pierre.kehr@gmail.com

1 Strasbourg, France 